\title{
Nuanças e estratégias que circundam o conhecimento tácito
}

\section{RESUMO}

Este artigo reflete a respeito das controvérsias da terminologia "gestão do conhecimento" por diversas áreas, usando a perspectiva filosófica de Michael Polanyi sobre conhecimento tácito, com base no insight "sabemos mais do que falamos". Segundo esse autor, o conhecimento tácito referese ao que o indivíduo adquiriu com sua experiência de vida, e a dificuldade em formalizá-lo existe porque é subjetivo e constitui as habilidades do indivíduo, sendo esses os principais elementos da discussão. Com base nos estudos de Polanyi, indaga-se: é possível gerenciar conhecimento? Por meio de revisão de literatura selecionada intencionalmente, em estudos nas áreas de administração e ciência da informação, apresentam-se posicionamentos divergentes acerca da gestão ou da criação e de estratégias empregadas pelas organizações para ampliação de conhecimento. Conclui-se, com base no cotejamento das ideias de Polanyi e dos autores pesquisados, que as estratégias, ao menos na literatura selecionada, focalizam metodologias que conduzem à criação de conhecimento e não à gestão, como algumas vezes são denominadas.

Palavras-chave: Conhecimento tácito. Epistemologia de Michael Polanyi. Criação de conhecimento. Gestão de conhecimento. 


\section{PRESSUPOSTOS INICIAIS}

Michael Polanyi (1891-1976) é um dos cientistas que aprofundou estudos sobre o conhecimento. O seminal insight que o motivou a publicar o famoso livro The tacit knowledge resume-se na frase: we know more than we can tell (POLANYI, 2009, p. 4), que, inserida no Google, em setembro de 2014, soma mais ou menos 80.100 resultados associados ao autor e a 89.200 .000 sem indicação de autoria. A expressão é usada para explicitar suas ideias, e os números evidenciam a citação por acadêmicos de áreas como ciência da informação, gestão, economia, psicologia cognitiva, filosofia, dentre outras.

O amplo interesse vincula-se a que Michael Polanyi, em sua existência, continuou desenvolvendo ideias com fertilidade e originalidade, disseminando escritos que perpassam a química do líquido hidrocefálico, estudando a físico-química do cérebro, e, em suas investigações e incursões pela filosofia, ele se volta às questões relacionadas ao conhecimento. Perseguiu por anos a economia, a política e as ciências sociais, tendo na Universidade de Manchester a disciplina Estudos Sociais, criada especialmente para ele. Médico, filósofo, professor, pesquisador, sua grande questão de pesquisa, como afirmado, resumia-se em compreender o conhecimento pessoal e tácito. A despeito de seus esforços, e das pesquisas daí advindas, não há, ainda, concretude em como o conhecimento formase na mente, mesmo que a psicologia continue pesquisando acerca desses aspectos.

$\mathrm{Na}$ administração e na ciência da informação, os estudos tentam demonstrar como se realiza a gestão de conhecimento nas organizações. Isso fornece combustível essencial para estudiosos das áreas indicadas de vários países posicionarem-se das mais diversas formas, seja a favor, seja em oposição, ampliando a quantidade de citações sobre conhecimento tácito e sobre a teoria de Polanyi $(1962,1966,1969,2009)$. Logicamente isso acontece porque ele é um cientista que fornece vasto material para a continuidade de estudos nessa área.

Para continuar ilustrando a produção científica que utiliza as ideias de Michael Polanyi, sobre conhecimento tácito, encontramos 162 resultados, em levantamento realizado na Web of Science, utilizando o nome do autor, no campo topic, desde 1995, com crescente destaque de citações entre 2005 e 2012, o que aponta a atualidade das ideias.

Ele inicia a ideia de conhecimento tácito com base no paradoxo de Menon, de Platão, quando este afirma que antes de nascermos existimos em outros seres ou em outras formas. De acordo com Polanyi (2009), se assim fosse, conduziria a inferir que buscar conhecimento é absurdo, já que o traríamos ao nascer, portanto, dispensaria a pesquisa (ou o estudo como troca de informação para ampliação do conhecimento, ou ainda as relações sociais nas quais haveria a possibilidade de aprender e apreender). A segunda discordância com Platão encontra-se no fato de que, por haver conhecimento, inexistiria a possibilidade de busca, não se necessitaria buscá-lo; por conseguinte, inexistiria, também, a expectativa de encontrá-lo.

Segundo o citado autor, temos ambos: o conhecimento e ideias sobre o que desejamos conhecer. O conhecimento tácito diz respeito ao que o indivíduo adquiriu com sua experiência de vida. A dificuldade em formalizá-lo existe porque é subjetivo, faz parte do conjunto de habilidades do indivíduo. $\mathrm{E}$ a melhor forma de transmiti-lo é pela oralidade, no contato e convivência com as pessoas, pelas interações sociais (POLANYI, 2009).

Ainda discordando de outro argumento de Platão, ao afirmar que o conhecimento tácito é a parte central do conhecimento, Polanyi (2009) esclarece que isso implica outro paradoxo, porquanto o ato de processar ou formalizar conhecimento excluiria/destruiria o conhecimento tácito e, excluindo-o, decreta-se a autodestruição do conhecimento. Na sua teoria, o conhecimento humano emerge da visão harmoniosa da existência do pensamento permeado pelo conhecimento universal. A estrutura do conhecimento tácito mostra que todo pensamento contém componentes dos quais estamos subsidiariamente cientes do conteúdo principal; entretanto, todo pensamento habita também em suas zonas subsidiárias, como se fossem partes de um todo.

Essas explicitações sobre conhecimento, adotadas ora por correntes filosóficas que defendem a interlocução da razão, ora pelos que defendem a mediação da experiência, fazem surgir o racionalismo e o empirismo, respectivamente. E essas permeiam os estudos das teorias principalmente quando tratam da formalização, da gestão e da transmissão do conhecimento no âmbito organizacional.

Nossa curiosidade intelectual é despertada por duas razões. A primeira refere-se à expressão "gestão do conhecimento", existente em linhas de trabalho de sociedades científicas, títulos de disciplinas em programas de graduação e de pós-graduação de instituições de ensino superior, denominações de grupos de pesquisa em áreas como as nomeadas. E há áreas que tratam do mesmo fenômeno, mas com a denominação de criação ou geração de conhecimento, motivo pelo qual nos dedicamos a esclarecer tais aspectos nos quais residem o objetivo e foco desta revisão.

A segunda razão advém da verificação da expressiva produção acadêmica sobre o tema gestão do conhecimento. Em levantamento realizado em 21 de dezembro de 2014 na Web of Science, foram 
encontrados 1.267 artigos com o termo knowledge management no campo título, publicados entre 1999 e 2014. Na área de Information Science and Library Science, foram publicados 305 artigos que discutem gestão do conhecimento, os quais incluem temas como software, estratégias de gestão, ontologia, práticas gerenciais e inovativas, metodologias para estimular a criação e compartilhamento de conhecimento nas organizações, discussões epistemológicas sobre conhecimento tácito e explícito. O número de artigos sofre ínfima redução, passa para 301 resultados, quando usado filtro para artigos em inglês, português e espanhol.

Assim, este texto baseia-se em literatura científica com visões contraditórias acerca da gestão do conhecimento. Primeiramente, expõe algumas expressões utilizadas pelos autores e que revelam conceituação sobre conhecimento tácito e/ou outras expressões que o adjetivam. Na sequência, apresenta pesquisas que questionam a gestão do conhecimento em organizações, sublinhadas pelos relatos sobre dificuldades para realizar tal gestão. Por fim, relaciona estratégias para socialização e interação de práticas e experiências, dentre os estímulos que promovem a criação e a ampliação do conhecimento.

Em alguns textos, os conceitos e seus respectivos autores revelam-se contundentes, porquanto se baseiam em teorias ou em como os teóricos os definem e os usam. As reflexões embasadas pelas ideias de Michael Polanyi fazem entender que as técnicas e estratégias, ao menos na literatura selecionada, focalizam metodologias que conduzem à criação de conhecimento e não à gestão do conhecimento, como algumas vezes são denominadas.

\section{CONHECIMENTO TÁCITO}

Os estudiosos continuam tentando entender como o conhecimento se forma na mente, as dificuldades em aprender e apreender, e por que ocorrem distorções. Algumas explicações são fornecidas por Simon (1957) ao popularizar a noção de que o mundo é complexo e, em contrapartida, o cérebro humano tem limitações para processar informações, havendo perfeita concordância quanto à dificuldade de processar ou de formalizar o conhecimento entre Polanyi $(1962,1966$, 1969, 2009) e Simon (1957). O homem, como ser racional, desenvolve esforço para tomar decisões coerentes sem reproduzir as informações da forma como as recebe, mas sim adequando-as às necessidades específicas com o que existe no seu intelecto. Isso explica a diversidade de estratégias ou estratagemas utilizados quando necessita agir em determinadas situações.

Especificamente sobre conhecimento tácito, Castillo (2002) afirma que, entre os pesquisadores das áreas da psicologia e da administração, há uma quantidade de fontes que conduzem a um core de múltiplas visões. Oferece três sugestões para alcançar a unidade e clareza do conceito de conhecimento tácito. A primeira sugestão denomina de Tipologia de Conhecimento Tácito, categorizando-o em quatro dimensões:

a) Pessoal, inefável e indescritível, impossível de ser escrito ou de ser verbalizado de alguma forma.

b) Sociocultural, pertencente a alguém que constitui parte e parcela do sistema cultural e social.

c) Semântico, pode ser verbalizado e, por meio do simbolismo, distingue comportamentos peculiares, desnecessariamente mencionados como conhecimento.

d) Sagaz, caracteriza alguém que, ao ser observado, se apresenta como sendo a forma pura da sagacidade e da habilidade.

Ao exemplificar cada uma das dimensões, Castillo (2002) cita diversos autores, para reafirmar que Polanyi não estava sozinho em suas ideias, e apresenta a segunda sugestão, denominando-a de A Prova de Fogo do Conhecimento Tácito. O teste apresenta-se em forma de questionamentos. Se o conhecimento é tácito ou é implícito, para quem ele é tácito ou para quem é implícito? Se o conhecimento envolve alguma habilidade, o conhecimento articula-se na reflexão? Será que o conhecimento emana de um comportamento automático ou de um pensamento profundamente enraizado? Será que o conhecimento tem mesmo base na experiência? (CASTILLO, 2002).

Tais argumentos não garantem que se possa responder se as perguntas realmente ajudariam a identificar as formas tácitas de conhecimento, se as formas tácitas englobam todos os aspectos referentes ao conhecimento tácito, ou ainda, se é necessário estabelecer padrões sobre conhecimento. Por outro lado, ao detalhar a terminologia semântica, Castillo (2002) claramente refere-se a conhecimento explícito (que tanto pode ser pessoal, como sociocultural), como aquele que o conhecedor pode falar sobre ele.

Como última sugestão, Castillo (2002) apresenta Uma Chamada para a Ação, conclamando gatekeepers, editores e avaliadores de periódicos como disseminadores de ideias para discutir conhecimento tácito como fenômeno ou metáfora. Isso porque, segundo ele, Polanyi não incluiu 
a habilidade para abstrair significado das palavras, quando propõe o conhecimento tácito, embora em artigo escrito em 1964 e publicado em janeiro de 1966, em The Journal of the Royal Institute of Philosophy, sob o título: The logic of tacit inference, ele admita haver implicações mais amplas do que as que ele pretendeu incluir no conceito de conhecimento tácito. Para Polanyi, essas ideias expandem a teoria do conhecimento em nova direção, mas não exigem purificar a ciência inserindose referências à mente ou à estrutura finalística dos seres vivos.

Ainda no mesmo artigo, Polanyi (1966), tomando emprestados termos da anatomia, postula que o conhecimento tem dois componentes: proximal (subsidiário) e distal (focal), existindo entre eles uma relação funcional. $O$ autor exemplifica no modo como reconhecemos um rosto, confiando em diversas características (cor dos olhos, formato do nariz, que são os aspectos subsidiários). No entanto, o que queremos ver é o componente distal, o rosto, e não suas características, percebidas de modo subsidiário. Além de funcional, a relação entre os dois componentes é semântica, uma vez que o distal confere significado ao proximal, razão por que podemos afirmar que a percepção é sempre significativa, porque integra, num ato perceptivo, elementos particulares, fazendo sentido inteligente numa forma ou padrão abrangente, por outro lado também significantes por serem importantes para a inteligência. Assim, o significado não é mero equilíbrio de forças, é algo que pode ser captado, ou criado, ou percebido por uma mente que o autor denomina conhecimento from-to, uma vez que sua estrutura funcional incorpora um "de" subsidiário e um "para" focal, integrando um ao outro, pelo ato de alguém.

Podemos, ainda, comparar a situação a uma tríade, cujos componentes são a pessoa que conhece, o foco e os pormenores subsidiários. A relação de-para, bem como a tríade, desaparece quando o conhecedor muda seu foco de atenção para os indícios subsidiários. Por essa razão, por não podermos encontrar os subsidiários essencialmente, por não serem especificáveis, eles se apresentam de dois tipos. O primeiro deles em virtude da dificuldade em reconstituir os subsidiários, dificuldade comum, mas não universal; o outro tipo deve-se a um senso de privação necessário, em princípio, absoluto (SAIANI, 2004).

Nessa direção e em tese para doutoramento, Jha (1995) explica que a formalização de Polanyi (1966) da tríade tácita tem o significado de inferência tácita, seu termo lógico para integração. Essa integração é ancorada e evocada pelo significado do foco de atenção e, no sentido que desenvolveu em sua filosofia The tacit dimension, pertence ao organizador, vivendo, dirigindo um ato de autotransformação em busca de significado, cujo objetivo é encontrar a verdade (JHA, 1995).

Nesse sentido, talvez haja a possibilidade de associar as ideias de Rojas (2005), ao se referir à informação e ao conhecimento como partes da tríade informação, conhecimento e valor. $\mathrm{O}$ autor entende a informação como uma qualidade secundária de objetos particulares. Sua perspectiva é essencialmente dialética para informação, vendo-a como a união de dois extremos, os elementos objetivos (dados) e subjetivos (as estruturas interpretativas dos sujeitos). Reconhece a existência de uma dimensão objetiva, mas também contempla a subjetividade dos sujeitos que vão construindo valores (tais como beleza, verdade, bondade e - poderíamos acrescentar - informação). Na construção teórica, o autor mobiliza conceitos, como inferência, assimilação, adaptação, imaginação e criatividade. Algumas das ideias e dos conceitos utilizados por ele são assemelhados aos que foram defendidos pelo criador do conceito de conhecimento tácito. Mas, similarmente a Castillo (2002), permanecemos questionando, se conhecemos por meio da informação (dimensão objetiva), se na apreensão do conhecimento usamos toda nossa subjetividade, inclusive para conferir valor ou para não nos afastarmos do foco do conhecimento, como então se daria o gerenciamento do conhecimento?

Retornando a Polanyi (2009), ao desenvolver sua teoria, esclarece que conhecimento é um processo subconsciente sobre uma rede de coisas que nós conhecemos ou que deveríamos conhecer, especificando-o em tipologia e adjetivando-o em pessoal, tácito, científico, moral, social, da vida prática. Tipologia essa adquirida essencialmente da mesma maneira com forte base no conhecimento tácito.

Torres (1998), estudando conhecimento tácito e explícito, afirma que os seres humanos desenvolveram uma cultura hemiplégica constituída de mente e corpo para dar conta do status ontológico do ser humano. Assim, haveria dois tipos de conhecimento, o saber que e o saber como. O primeiro, teórico, associado à mente, e o segundo, ao conhecimento prático, objetivo, associado ao corpo, respectivamente, conhecimento tácito e explícito. Os defensores do conhecimento tácito dizem que ele é o único produto do pensamento intelectual por natureza e, ao defender o conhecimento explícito, afirmam que os seres humanos chegam ao conhecimento como consequência de vivenciar o lado qualitativo da experiência.

Ainda é o autor citado quem define conhecimento como um processo ativo, consciente, por meio do qual se adquire uma nova unidade de significado, implicando o estabelecimento de íntimas, 
mútuas e válidas correspondências entre o portador do conhecimento e o objeto conhecido. Surge em um tempo e espaço específicos; portanto, é histórico e perspectivo, falível, não absoluto e final, enfatizando a capacidade de estruturar a experiência por meio de conceitos, efeitos, causas, razões e leis científicas. Assim sendo, seus produtos são ideias e abstrações.

Por outro lado, o conhecimento é também explícito quando os seres humanos podem falar sobre ele, colocando sentido nas palavras daquilo que conhecem ou constroem, estabelecendo redes de conexões que descrevem, explicam e predizem. É o reconhecimento de uma habilidade de executar uma ação, que é explícita porque tem a possibilidade de ser descrita por meio das metodologias que lançam mão dos métodos dedutivos e indutivos da razão. Portanto, é igualmente subjetivo, prático ou pessoal, associado a competências de alguma performance, e tácito pela maneira de proporcionar uma visão de mundo muito mais intuitiva que a do conhecimento explícito. Dessa forma, o conhecimento tácito é conhecimento vivido por conta da participação na performance, contribui para dar sentido à experiência de modo profundo e subjetivo, e permite aos indivíduos o acesso ao que estão realizando (TORRES, 1998).

Goodman (2003, p. 133) faz importante acréscimo à frase do autor da gênese do conhecimento tácito:"nós não somente conhecemos mais do que podemos falar, mas também dizemos mais do que conhecemos". Esse autor salienta que Polanyi (1962) atribuiu ao homem superioridade intelectual, distinguindo-o de outros animais pela capacidade de uso da linguagem. Sem ela, nossa experiência de mundo seria similar à de outros primatas. É a linguagem que aumenta nossa capacidade de reflexão abstrata. E, respaldado em Cassirer e Wittgenstein, afirma que somente se o processamento das representações simbólicas estiver relacionado ao contexto no qual elas são significantes a semântica torna-se possível (GOODMAN, 2003).

Cientistas da informação e economistas concordam que o conhecimento acontece na mente. Há uma ação para identificar sua existência materializada pela informação, encontrando-se a distinção na terminologia usada pelos dois grupos de profissionais e na possibilidade de transmissão considerada mais difícil pelos economistas. Informação e conhecimento materializam uma interação entre fontes de inovação e dinamizam a geração, aquisição e difusão de tecnologias. Inovações tecnológicas são conhecimentos aplicados a novas formas de produzir bens e serviços. Inovações organizacionais são novos meios de organizar empresas que produzem, fornecem e comercializam bens e serviços. Essas inovações são complementares às transformações políticas e sociais do avanço econômico. Este é percebido como produto das orientações e da interação do ambiente histórico, político, social e econômico (LASTRES; FERRAZ, 1999).

Embora muitos termos sejam utilizados para descrever o conhecimento, tais como pessoal, sociocultural, semântico, sagaz (CASTILLO, 2002); objetivo, subjetivo (ROJAS, 2005); teórico ou tácito e prático ou explícito (TORRES, 1998); científico, moral, social, da vida prática, pessoal, tácito, distal e subsidiário (POLANYI, 1966); o mais utilizado, e também o mais controverso, é a distinção entre tácito e explícito. Embora esses tenham sido anteriormente conceituados, pode-se ainda utilizar uma definição simples, o conhecimento tácito é aquele que é entendido por não ser expresso abertamente, é surdo ou não dito. Um exemplo pode ser o conhecimento de que um falante nativo tem de outra língua. O conhecimento explícito, por outro lado, é o que pode ser expresso de forma clara, completa. Um exemplo pode ser o conhecimento que pode ser formalmente expresso e transmitido a outras pessoas por meio de manuais, especificações, regulamentos, normas ou procedimentos. Há ainda outra dupla de termos que podem encontrar semelhanças com os conceitos anteriormente definidos, que são informação e conhecimento (BROOKES, 1980; LASTRES; FERRAZ, 1999; BARRETO, 2003; SILVA, 2006) conceituados na sequência. Acreditamos que nessas tipologias e em suas conceituações, situam-se os problemas que se relacionam à gestão e à criação do conhecimento, este componente de suma importância para as organizações, nos tempos atuais, cabendo então o questionamento que conduz ao próximo item.

\section{GERENCIA-SE CONHECIMENTO?}

Hessen (2000) apresenta diversas correntes teóricas que explicam a origem do conhecimento sob a perspectiva fenomenológica, em que algumas defendem o racionalismo e outras o empirismo. As explicações quanto à essência do conhecimento podem ser sumarizadas em pré-metafísicas (objetivismo e subjetivismo), metafísicas (realismo, idealismo, fenomenalismo) e teológicas. Essa divisão contribui para a manutenção das visões dualistas entre sujeito e objeto, forma e conteúdo, razão e experiência, matéria e espírito, essência e aparência. Distinguir as diferenças e interrelacionamentos é importante; contudo, o privilégio por esta ou aquela abordagem dicotômica impede a compreensão dos contraditórios como necessários à percepção da realidade, seja ela qual 
for, para o indivíduo que a observa (SILVA, 2014).

Nonaka e Takeuchi (1977) afirmam que a filosofia ocidental separa razão e experiência; entretanto, a união das duas permite conhecer e interagir com a realidade. Em síntese, a criação do conhecimento requer ambas as habilidades: empíricas e cognitivas. Isso induz ao entendimento de que as organizações devem criar condições ou estratégias que permitam o livre fluxo entre a experiência vivida e o sujeito que a compreende e dissemina. Em outras palavras, os autores denominam gestão de conhecimento, mas na realidade propagam estratégias e técnicas para criação de conhecimento, conforme se depreende do conceito de "Ba" (NASCIMENTO, 2004).

É com base nas ideias dos autores citados que se conduz a discussão acerca das dificuldades e/ou impossibilidades de gerenciar conhecimento. Iniciando-a por Silva (2006), ao afirmar que há um entrelaçamento generalizado do senso comum, entre informação e conhecimento, sendo essa a forma assimilada e usada pela quase totalidade das pessoas. Inclusive esse entrelaçamento estaria contido na fórmula de Brookes (1980), exprimindo a passagem de um estado de conhecimento para novo estado de conhecimento, pela utilização da informação. Ainda de acordo com Silva (2006), a fórmula oferece motivo para sua validação tanto quanto para se desconfiar dela pela circularidade existente entre informação e conhecimento. A validação estaria na afirmação de que o conhecimento desenvolve-se da inevitável informação e na possibilidade de a fórmula possuir todos os elementos instrumentais e necessários ou indispensáveis, o que geraria desconfiança.

Autores como Birkinshaw (2001) e Navega (2003) demonstram, por meio de pesquisas, as dificuldades para gerir conhecimento. O primeiro autor explica que a chave do problema é que o conhecimento é central no fazer de uma organização, não podendo ser separado e aceito como um simples processo de negócio ou de um sistema de administração. Afirma, ainda, que, em todas as companhias, o conhecimento é gerido por redes informais que envolvem e desenvolvem novos instrumentos, mas eliminam formas antigas de trabalho. Resulta em que, ao mudar o sistema de gestão do conhecimento da empresa, é necessário mudar a cultura organizacional, fundamentada no comportamento das pessoas, e levando tempo para consolidar nova cultura, especialmente quando as soluções não são simples para promover as mudanças desejadas. Em pesquisa realizada em doze empresas de renome, Birkinshaw (2001) cita três possibilidades, que consideramos estratégias de criação ou de ampliação de conhecimento:

a) Interação entre os membros da empresa.

b) Interação com os arquivos da empresa.

c) Atualização, renovação e inovação da base de conhecimentos para além das fronteiras da empresa.

O segundo autor, embora também reafirme a dificuldade em gerenciar conhecimento, explica que o sucesso de uma eficaz gerência do conhecimento está em proporcionar um ambiente favorável ao desenvolvimento do ciclo criação/realização a cada um dos tipos de trabalhadores que necessitam ver satisfeitas suas principais necessidades. Na pesquisa, Navega (2003) considera três grupos de atores:

a) Aplicadores, responsáveis pelo repositório técnico e científico da empresa, acionados quando surge dúvida técnica sobre produtos ou serviços.

b) Consumidores, grupo de pessoas que procuram conhecimento para realizar a atividade-fim.

c) Geradores, os que são responsáveis pela criação de novos conhecimentos que ainda não fazem parte do repositório dos aplicadores.

São grupos que desenvolvem relações interpessoais para adquirir ou para gerar conhecimento. Portanto, nas duas pesquisas, é possível compreender que a transmissão do conhecimento ocorre sempre por intermédio de relações interpessoais ou da utilização do conhecimento codificado armazenado em arquivos. Entretanto, os autores não dizem que a interpretação a cada nova informação depende da carga anterior de conhecimento que alguém tenha adquirido, ou seja, acatando a fórmula de Brookes (1980). Igualmente não distinguem informação de conhecimento, ou a circularidade discutida em Silva (2006).

Por outro lado, há que considerar o que os economistas não ortodoxos destacam sobre o sentido econômico de informação e conhecimento. Esses distinguem o conhecimento codificado (igual a informação registrada ou transmitida oralmente sob a forma de linguagem) que pode ser comercializado, enquanto o conhecimento tácito está associado a processos de aprendizagem e depende de contextos e formas de interação social. O conhecimento tácito visto por Barreto (2003) depende da absorção de informações para que a estrutura cognitiva do indivíduo se modifique. Há unanimidade entre os economistas sobre formas de conhecer, a importância de geração de novos conhecimentos, sua introdução e difusão no sistema produtivo como citado por Lastres e Ferraz (1999).

Continuando sobre a distinção entre os dois conceitos, Foray e Lundwall (1996) explicitam que 
o conhecimento codificado ou informação é transmitido por intermédio de uma estrutura que reduz e converte o conhecimento para facilitar o processo de transmissão, verificação, estocagem e reprodução. De acordo com eles, o conhecimento codificado pode ser transferido de longas distâncias e entre organizações, a baixo custo. Afirmam que, conquanto a possibilidade exista, conhecimento codificado não é facilmente trocado no mercado porque o vendedor guarda o acesso, dificultando ao comprador a distribuição entre os clientes potenciais.

Se o vendedor permite o acesso ao comprador, este detém a informação, não se fazendo necessária a compra. Arrow (1971) complementa, afirmando que a característica de intangibilidade da informação não impede que diversos agentes possuam e utilizem ao mesmo tempo a mesma informação. Por sua vez, o conhecimento tácito não pode ser transferido com a mesma facilidade, porque não se apresenta de forma explícita. Reforçando, este depende de formas de interações sociais e dos processos de aprendizagem, o que significa codificação em informação para ser transmitido.

Os autores das escolas do pensamento estratégico, Mintzberg, Ahlstrand e Lampel (2006), ao focarem metodologias para formulação de estratégias também admitem dificuldades no gerenciamento de conhecimento, identificando que as ocorrências externas influenciam e promovem, algumas vezes, distorções na mente, e noutras a possibilidade de integrar uma diversidade de informações complexas. Por conseguinte, corre-se o risco de compreensão distorcida quando fenômenos, como sabedoria experimental, discernimento criativo e síntese intuitiva são negligenciados ou ignorados.

Esses autores evocam a psicologia cognitiva e alertam que apresentam uma escola de pensamento, que resulta de reunião de pesquisas que se dividem em dois lados. Uma ala positivista, que trata o processamento e a estruturação do conhecimento de maneira objetiva em que a mente filma o mundo, aproximando-se ou afastando-se conforme a vontade de seu possuidor, e uma ala subjetiva, que procura entender a cognição como recriação do mundo, acreditando na hermenêutica que o cria. Mas também fazem referência a algumas observações limitantes: cognição como confusão; cognição como processamento de informações; cognição como mapeamento; cognição como realização de conceitos e, por último, cognição como construção, oferecendo maneiras como as pessoas lidam com informações, especialmente quando estas surgem do meio ambiente.

E o que mais importa para a ala objetiva, as observações limitantes, flui de todos os tipos de deturpações antes de serem decodificadas, enquanto para a ala subjetiva elas são interpretações do mundo como ele é percebido, difíceis de serem realizadas e difíceis de mudar, quase inviáveis (MINTZBERG; AHLSTRAND; LAMPEL, 2006).

A gestão do conhecimento pode ser vista como abordagem integrada para alcançar os objetivos organizacionais, colocando o conhecimento como novo fator de produção (AN ILLUSTRATED..., 2003). Este, por sua vez, dá suporte à criação, transferência e aplicação do conhecimento individual em processos valorativos de criação. $O$ Guia ressalta que isso somente ocorre em ambientes nos quais a cultura organizacional promove condições para tais atividades e para o processamento de informação e documentação.

Barradas e Campos Filho (2010) conduziram levantamento de tendências sobre a gestão do conhecimento no Brasil, no qual cotejaram as opiniões de trinta especialistas brasileiros com revisão de literatura nacional e internacional. $O$ estudo aponta duas tendências, a primeira referente a temas mais consolidados na literatura e presentes nos resultados da pesquisa, e outra por temas menos consolidados. Na categoria de temas consolidados, encontram-se: disseminação do tema, barreiras e dificuldades, medição de resultados e modismo. As respostas referentes às dificuldades foram agrupadas em seis categorias: cultura; comprometimento da alta direção; intangibilidade do processo; falta de conhecimento sobre gestão de conhecimento; educação formativa de base. A cultura organizacional representou $53,3 \%$ das respostas, confirmando a tendência da literatura. Destacam-se resultados referentes a controvérsias da mensuração da gestão de conhecimento. Os resultados da pesquisa apontam que $70 \%$ conseguem medir a gestão do conhecimento, mas poucos apresentam métricas consistentes, enquanto muitos esclarecem que estão pensando em fazer; nunca o fizeram, porém (BARRADAS; CAMPOS FILHO, 2010).

Relativamente à conceituação, o que é citado por muitos entrevistados e ratificado pela literatura é que a terminologia "gestão do conhecimento" é insuficiente em seu significado. O estudo foi realizado em 2010, e isso provoca uma reflexão sobre se houve ou há avanços teóricos ou se estes estão sendo confundidos com avanços práticos, pela inclusão de tecnologias que possibilitam troca de informação e de metodologias para compartilhar conhecimento em ambientes que oferecem condições para tal prática.

Constatamos que há imbricação do conhecimento tácito e do explícito, e ao se referir à gestão do conhecimento, os resultados da pesquisa e a literatura remetem a condições e ferramentas que criam, transmitem e trocam conhecimento, mas não significa gestão do conhecimento como 
geralmente se propaga.

A dicotomia entre conhecimento tácito e explícito é, de acordo com Leonard e Sensiper (1998), um espectro, num extremo completamente tácito, semiconsciente e inconsciente; no outro espectro, é quase explícito ou codificado, estruturado e acessível a pessoas que não são os que o originaram. Entre os extremos situa-se a maior parte do conhecimento que está em curso. Elementos explícitos são objetivos, racionais e criados no aqui e ali, enquanto os elementos tácitos são experienciais, subjetivos e criados no aqui e agora. Assim sendo, continuamos reforçando que há dificuldades empíricas e teóricas para gerenciar conhecimento, defendendo a criação e a socialização de conhecimento em vez da gestão.

\section{ESTRATÉGIAS PARA CRIAÇÃO DE CONHECIMENTO}

Polanyi (2009) desenvolveu sua teoria considerando o conhecimento científico, moral, social e da vida, e mostrou que todos eles são, na essência, o que chamou de conhecimento tácito. Ao falar sobre conhecimento tácito, o autor referia-se a um processo subconscious, como uma rede de coisas que conhecemos ou que inconscientemente poderiam existir, afirmando que conhecemos mais do que podemos expressar. Embora Polanyi não tenha vivido o início dos anos 1990, quando o termo "gestão do conhecimento" foi cunhado, ao explicitar sobre um processo inconsciente, ele se coloca em posição contrária à gestão do conhecimento, visto que tal atividade depende do planejamento e da execução de etapas, tornando-se procedimentos impossíveis de se realizar nas pessoas.

Birkinshaw (2001), no artigo em que busca sentido para as implicações práticas da gestão do conhecimento, realiza entrevistas com cinquenta executivos de grandes companhias, examinando as práticas de gestão do conhecimento, e os resultados de seus esforços, no mais das vezes, conduzem a um lugar entre desapontamento e aceitação. Confessa que, na pesquisa realizada, inexistem falhas graves; entretanto, também inexistem histórias de sucesso. De acordo com ele, o problema está em que a gestão do conhecimento é tão central para uma organização que se torna inseparável para ser aceita como procedimento de negócio ou de sistema administrativo. Assim sendo, a gestão do conhecimento promete mais do que oferece.

E continua o autor: em termos práticos há três elementos da gestão do conhecimento citados anteriormente. Primeiro, a empresa encoraja os indivíduos a interagir - trabalhar juntos num projeto, ou discutir suas ideias. Segundo, o sistema necessita codificar o conhecimento individual para ser usado por outros, não é fácil em razão de que a maioria do conhecimento disponível é originariamente tácita, isto é, reside profundamente no indivíduo que tem dificuldades para descrevê-lo ou expressá-lo. Numa interação bastante pessoal ou por arquivos explicitados, torna-se propriedade da organização e fonte-chave de vantagem. Terceiro, a organização necessita divulgar o conhecimento para fora de suas fronteiras como atualização e renovação de sua base de conhecimento.

Schartinger et al. (2002), em pesquisa para identificar as interações entre instituições de pesquisa e indústrias na Áustria, afirmam que o conhecimento tácito transfere-se no contato pessoal. Os autores citam algumas dessas técnicas: interaction, creation, generation, dissemination, diffusion, transfer, sharing, flow e spillovers. Esclarecem, ainda, que os canais variam de intensidade nas relações pessoais. As indústrias, ao usarem diferentes canais, lançam mão simultaneamente de uma variedade de estratégias, resultando na eficiência e no acesso a diferentes tipos de conhecimento científico e tecnológico que se encontram, também, em diferentes estágios de inovação.

Atentando para as estratégias e/ou para as técnicas descritas, tem-se a clareza de que o estímulo para as pessoas interagirem recebe denominação variada, tais como comunidades de prática (CoP), as quais permitem a criação de conhecimento (WENGER, 1998). Navega (2003) e Krogh, Ichijo e Nonaka (2000) referem-se à manutenção de um ambiente favorável, ou a um contexto adequado. Os três autores citam ainda as seguintes técnicas: incutir a visão de conhecimento, gerenciar as conversas, mobilizar os ativistas de conhecimento, globalizar o conhecimento local. Pode-se, além disso, acrescentar outras técnicas, como o sense making e a bricolagem, utilizadas para estimular a criação de conhecimento.

Dedicando seus estudos a essa crença, os três autores reforçam o papel que o conhecimento desempenha ao considerar as estratégias de sobrevivência e as de progressão. Ao distinguir as razões, os gestores compreendem que o"conhecimento tácito tem muito potencial, por vezes é subutilizado ou ativamente ignorado nos modelos estratégicos tradicionais de criação de conhecimento" (KROGH; ICHIJO; NONAKA, 2000, p. 74). E, tomando como base a cultura organizacional, eles afirmam que, em um contexto de negócios, o conhecimento pode ser dividido em duas grandes categorias: o conhecimento único, realizado exclusivamente pela empresa, e o conhecimento público, realizado por vários concorrentes. Para que o conhecimento único torne-se uma fonte de vantagens competitivas 
sustentáveis deve satisfazer a três critérios: deve ser valioso, difícil para os competidores imitarem e difícil de substituir. Ou seja, absolutamente subjetivo, dependente de estratégias metodológicas para ampliar experiências adquiridas.

Klint e Verhoef (2002), embasados na obra de Krogh, Ichijo e Nonaka (2000), relacionam as etapas de criação de conhecimento - compartilhar conhecimento tácito, criar conceito, justificálo, construir o protótipo e nivelar e ultrapassar o conhecimento existente - com os facilitadores -, desenvolver a visão, gerenciar conversas, mobilizar ativistas, criar contexto adequado e globalizar o conhecimento local. Isso permite entender como cada facilitador contribui em diferentes graus para cada etapa da criação. A seguir, expomos os facilitadores de forma sintética, contudo, incorporando outros autores.

\subsection{Incutir a visão de futuro}

Esta estratégia é utilizada pelas organizações nos tempos atuais. Aliás, as organizações, ao fazerem o marketing para divulgar suas atividades, apresentam-se citando sua missão e visão. A missão representa o que a organização é, focaliza o que ela realiza e deve ser simples, operacional e clara, caso contrário não passará de boas intenções. Nesse sentido, ela deve focalizar também quais seus principais valores, o que a diferencia dos concorrentes, em síntese qual é o negócio da empresa e qual não é o negócio da empresa.

$\mathrm{Na}$ visão, ela deve focar no que pretende ser, no futuro. Tal visão de futuro deve ser clara, compreensiva, sucinta e realista. No entanto, é necessário que os membros da organização incumbamse e envolvam-se com as mudanças que podem vir do ambiente externo e das exigências do mercado, da inovação de tecnologias ou não; portanto, os recursos humanos devem ter qualificação desejável e quantificação disponível, e ainda necessitam do apoio institucional e político da organização. Isso porque nenhuma organização se mantém em um mercado em constante inovação sem mudança. Ao estabelecer a visão, afirma aonde pretende chegar, estimulando seus componentes a utilizarem o conhecimento de que disponham e as estratégias que possam aplicar para alcançá-lo. É uma técnica para fazer com que todos estejam por todo tempo criando, desenvolvendo e/ou ampliando ideias e conhecimentos, senão imbuídos e antenados com o que há por ser atingido em prol do atendimento da mudança futura da organização.

Essa técnica ou estratégia é utilizada pelos indivíduos de per si, em interação grupal ou em sociedade. Todos querem alcançar mudanças e, de preferência, para melhor, provocando o uso do conhecimento para seu alcance ou, em outras palavras, garantindo a sobrevivência no presente e avançando para o futuro. Falar sobre o poder do conhecimento tácito ou da vantagem competitiva para um período de tempo muito distante deve ser estimulante e construtivo, por isso a criação do conhecimento necessita ser parte integrante das estratégias da organização como indicado na proposta de visão realizada por Krogh, Ichijo e Nonaka (2000).

\subsection{Comunidades de Prática}

Outra possibilidade para gerar conhecimento é oferecida pelas CoPs, em que as pessoas desenvolvem o conhecimento por meio da interação com os outros em um ambiente no qual o conhecimento é criado, nutrido e sustentado. Wenger (1998, p. 52) "considera a prática como uma experiência da vida cotidiana". Ele afirma que o significado de uma experiência é o que Ihe interessa e que ele está localizado em um processo chamado de negociação de significado. Esta envolve a interação de dois processos, participação e reificação, que formam uma dualidade.

A noção de dualidade é vital para alavancar o conceito de CoP, pois que a participação é um dos elementos-chave do processo de negociação de significado. Segundo o autor, a participação é mais do que se engajar em atividades com um grupo selecionado de pessoas. Aprender a participar é um processo em que as pessoas não são apenas os participantes ativos das práticas de uma comunidade, mas são também as que, por meio das práticas, desenvolvem suas próprias identidades em relação a essa comunidade. No entanto, a experiência social de viver no mundo, em termos de participação em comunidades sociais e envolvimento ativo em organizações sociais, não necessariamente equivale à colaboração, e isso porque pode envolver todos os tipos de relações conflituosas e harmoniosas, íntimas e políticas, competitivas e cooperativas (WENGER, 1998).

Em etapa posterior, o autor concentrou-se na reificação para dar forma concreta a algo abstrato. Ele refere-se ao processo de dar forma à nossa experiência por meio da produção de objetos que cristalizam a experiência em coisificação. O termo "reificação" cobre ampla gama de processos que incluem concepção, denominação e ações, tais como codificar, descrever, perceber, interpretar, utilizar, reutilizar, decodificar e reformular (WENGER, 1998). 
O autor enfatiza que a participação e a reificação são analiticamente inseparáveis; no entanto, na realidade uma não substitui a outra. A participação é indeterminada sem reificação e vice-versa. Elas não constituem uma dicotomia, embora possam diferir na forma como influenciam a negociação de significado em um ambiente particular. A reciprocidade é essencial na participação para que os membros de uma comunidade reconheçam-se em si e por meio da reificação. Os sentidos são projetados para o mundo exterior e atingem existência independente, assim o conhecimento é gerado.

Para conduzir a conexão entre as estratégias de criação de conhecimento, a CoP pode iniciar buscando focar na visão da organização. Os primeiros encontros podem realizar-se em espaço no qual convivam externamente à organização, como encontros de happy hour e, à medida que a CoP se fortalece, buscar local mais adequado, até porque se acredita que os compartilhamentos também se tornam mais acalorados.

\subsection{Criar o contexto adequado}

O conceito de Ba, conforme explicitado por Nonaka e Konno (1998), é um espaço compartilhado para as relações que emergem. Esse espaço pode ser físico (um escritório, espaço de negócios (redes), etc.); virtual (um e-mail, uma teleconferência, etc.), mental (das experiências compartilhadas, das ideias, dos ideais) ou uma múltipla combinação destes. Em síntese, deve ser um espaço compartilhado, que serve de base para a criação de conhecimento individual ou coletivo.

Krogh, Ichijo e Nonaka (2000) afirmam que não somente um lugar deve ser adequado para que os ativistas do conhecimento possam socializá-lo, mas também o contexto deve ser estimulante para que as trocas possam acontecer. Ba essencialmente serve como fundamento para a criação de conhecimento, definida como rede de interações, na organização ou em encontros face a face, desde que a interação e a comunicação entre as pessoas aconteçam.

O contexto pode ser criado intencionalmente pelos gestores e produtores de conhecimento para facilitar espaços apropriados, promover a interação entre os membros da organização por meio de forças-tarefa, equipes e retiros. O trio de autores ainda chama a atenção que esse contexto pode parecer similar à CoP. Mas eles esclarecem que a CoP implica que os membros do grupo se unam para aprender as práticas e, gradualmente, memorizar as atividades do trabalho, enquanto no contexto adequado há o compartilhamento para ajudar a criar novo conhecimento pela interação face a face ou virtual. E fazem a proposição de interação em uma espiral de conhecimento, importante para que todo o processo de mantê-la continue da origem, para a conversação, para a documentação até a internalização e novamente se torne originário, oportunizando ao conhecimento criado o contínuo desenvolvimento.

a) Interação originária - quando os indivíduos compartilham sentimentos, emoções e experiências. A interação face a face é a forma de capturar o máximo dessas sensações físicas e reações emocionais necessárias para transferir conhecimento tácito. Enfatizam-se as ações que inspiram cuidado, confiança e compromisso para permitir o compartilhamento de conhecimento.

b) Conversação - para compartilhar os modelos mentais e as habilidades dos membros individualmente, reforçando a conversão do conhecimento tácito em conhecimento explícito, em que as habilidades e o uso de uma linguagem comum podem vir à tona. Há aqui a necessidade de maior conscientização do que é fomentado nas interações originárias.

c) Documentação - deve ser coletiva e virtual, porquanto o conhecimento explícito deve ser transmitido a grande número de pessoas por meio de documentos escritos, e tal interação envolve a combinação e a apresentação do conhecimento explícito existente. Pode ser respaldada por muitas firmas e pela tecnologia da informação como redes on-line e groupware.

d) Internalização - que é tanto individual como virtual. À medida que as pessoas leem os documentos ou assistem aos vídeos, fica mais fácil de internalizar o conhecimento explícito que se encontra ali presente. Melhor dizendo, o conhecimento, ao ser bem comunicado pelas organizações via manuais, e-mails, vídeos ou outras mídias, tem mais possibilidades de ser internalizado (KROGH; ICHIJO; NONAKA, 2000).

Cada organização tem seu próprio estilo para criar as interações e utilizar a diversidade de experiências, obrigações e verdades, e, dessa forma, estabelecer suas redes. Portanto, criam o contexto baseadas na visão e nas estratégias de negócios. Ou, em outros termos, o que dita o contexto adequado deve ser seguido ou readequado corretamente pela estrutura organizacional.

\subsection{Mobilizar os ativistas de conhecimento}

Este item descreve como os agentes sociais participam dos grupos que objetivam teorizar 
interesses, construir alianças, mobilizar o apoio e desacreditar seus opositores. Tem como base Krogh, Ichijo e Nonaka (2000), bem como Klint e Verhoef (2002), uma vez que, segundo esses autores, os ativistas do conhecimento interferem no que as pessoas acreditam ser seus interesses, quem elas acreditam serem seus aliados e como justificam as mudanças que buscam. E, ainda, nas formas que elas encontram para dirigir, refletir sobre as circunstâncias e como isso deve resultar numa política que não, necessariamente, se encontra no domínio material.

Ativistas do conhecimento são pessoas que facilitam o processo de criação do conhecimento. Elas podem agir como catalisadoras, reunindo pessoas com determinadas habilidades para criar conhecimento. Também podem atuar como coordenadoras, criando o contexto certo e fazendo conexões com a visão global do conhecimento, bem como com as iniciativas locais relacionadas à organização. Elas podem atuar como comerciantes, atraindo a atenção para uma iniciativa em outras partes da organização.

Ao contrário dos escritórios tradicionais de conhecimento que acreditam em controlar o processo de criação de conhecimento, o ativista do conhecimento objetiva permitir que a criação ocorra, buscando contexto e condições. Conforme Klint e Verhoef (2002), a sociologia mostra, por intermédio de resultados de estudos, que há pessoas que conseguem empregos por meio dos contatos pessoais. A maioria das ligações pessoais não são o que consideramos (amigos) laços fortes; porém, encontram-se no que se pode denominar de laços fracos. Esses laços fracos situam-se fora do círculo interior da pessoa, entretanto, têm conhecimento aproximado do conhecimento das pessoas. Esses dois autores afirmam que Granovetter (1973), estudando os laços sociais na rede, descobriu e denominou a força dos laços. Os laços fortes, nessa concepção, seriam aqueles nos quais há maior intimidade e proximidade entre pessoas. E os laços fracos são os constituídos de relações dispersas entre usuários da rede.

Assim, quanto maior o número de conhecidos de uma pessoa, mais poderosa ela se torna. Isso porque os ativistas de conhecimento têm como objetivo profissional conectar as pessoas certas e, ao fazê-lo, podem tornar-se socialmente poderosos. O que mantém esses grupos é a adequada gestão para evitar que pessoas sem potenciais compromissos de concentração de energia e/ou sem objetivos de longo prazo participem do compartilhamento de conhecimento.

\subsection{Globalizar o conhecimento local}

Este é o último capacitor dos cinco utilizados para ajudar a transferir o conhecimento criado localmente, por meio do pensamento que talvez as organizações o distribuam globalmente. Todo fenômeno de conhecer e a teoria da distribuição estão aplicados nessa estratégia para explanar como as inovações são difundidas na sociedade e nas organizações.

O conhecimento, para ser transferido entre um criador e um receptor, sofre barreiras e interveniências psicológicas, sociais e técnicas. Isso é considerado como um processo em três estágios: desencadeando o processo de reconhecimento de uma oportunidade de negócio e relacionando-a com o conhecimento disponível em alguma parte da empresa (usando o conhecimento dos ativistas, por meio de oficinas, em quadros de avisos, e assemelhados), embalando e expedindo o conhecimento, e recriando-o no local do receptor.

A ideia subjacente é que a transmissão de conhecimento não é uma operação de cópia literal do remetente ao receptor, mas deve considerar o conhecimento implícito e explícito tanto do emissor quanto do receptor, bem como as circunstâncias locais em que o conhecimento volta a ser criado e aplicado. 
Quadro 1 - Relação entre as etapas de criação de conhecimento e os facilitadores do conhecimento

\begin{tabular}{|c|c|c|c|c|c|c|}
\hline \multicolumn{7}{|c|}{ Knowledge Creation Steps } \\
\hline & & $\begin{array}{c}\text { Sharing tacit } \\
\text { knowledge }\end{array}$ & $\begin{array}{l}\text { Creating a } \\
\text { concept }\end{array}$ & $\begin{array}{c}\text { Justifying a } \\
\text { concept }\end{array}$ & $\begin{array}{l}\text { Building a } \\
\text { prototype }\end{array}$ & $\begin{array}{c}\text { Cross-Leveling } \\
\text { knowledge }\end{array}$ \\
\hline \multirow{5}{*}{$\begin{array}{l}\text { Knowledge } \\
\text { Enablers }\end{array}$} & Instill a Vision & & + & ++ & + & ++ \\
\hline & $\begin{array}{c}\text { Manage } \\
\text { Conversations }\end{array}$ & ++ & ++ & ++ & ++ & ++ \\
\hline & $\begin{array}{l}\text { Mobilize } \\
\text { Activists }\end{array}$ & & + & + & + & ++ \\
\hline & $\begin{array}{c}\text { Create Right } \\
\text { Context }\end{array}$ & + & + & ++ & + & ++ \\
\hline & $\begin{array}{c}\text { Globalize Local } \\
\text { Knowledge }\end{array}$ & & & & & ++ \\
\hline
\end{tabular}

Fonte: Klint e Verhoef (2002, p. 147)

Klint e Verhoef (2002) representam, no Quadro 1, a relação entre as etapas de criação de conhecimento e o que pode ser esboçado pelos facilitadores de conhecimento. Eles explicam que o campo vazio indica a ausência de correlação, enquanto + indica uma correlação moderada, e ++ uma forte correlação.

\subsection{Bricolagem}

A bricolagem é uma estratégia de criação de conhecimento que depende e pode ser realizada por um indivíduo que faz escolhas para a criação de algo que serve inicialmente a ele próprio. Em antropologia, bricolagem é a união de vários elementos para formação de um único. Na prática, atualmente, essa técnica engloba qualquer área de atividade, dos cuidados médicos ao design de interiores, da publicação à eletrônica.

A criação do conhecimento como prática social pode ser entendida como bricolagem na concepção de Certeau (1994), para o qual o conceito está relacionado à arte criativa do fazer e ao uso oportunista do tempo e do espaço, com base nas táticas cotidianas dos sujeitos. Isso implica pensar que mesmo em ambiente gerenciado/controlado podem surgir novas formas de interação não pensadas anteriormente, porque os sujeitos e seu conhecimento tácito podem remoldar de forma criativa e autônoma as fronteiras postas pelo próprio ambiente organizacional.

$\mathrm{Na}$ opinião de Castillo (2002), o conhecimento tácito que não pode ser escrito pode estar no coração da ideia de bricolagem. Ou seja, um bricoleur depende ou utiliza alguma forma de conhecimento profundo - que ele denomina de conhecimento tácito do tipo não escrito. $\mathrm{O}$ antropólogo Lévi-Strauss usou o termo "bricolagem" para descrever uma ação espontânea, além de estender o termo para incluir padrões característicos do pensamento mitológico, que desobedecem ao rigor do pensamento científico. O pensamento mitológico, criado pela imaginação humana, é baseado na experiência pessoal, sendo gerado pelo surgimento de coisas pré-existentes na mente do imaginador. Desse modo, a mitologia descreve o mundo por intermédio de narrativas (CASTILLO, 2002).

No mundo em que há poucas ferramentas linguísticas, faz-se necessária a utilização de metáforas e narrativas. Tanto que, na falta de uma palavra para o ato sexual, por exemplo, os gregos antigos lançaram mão de toda uma história fantástica para, enfim, chamá-lo de coisas de Afrodite.

Na Chamada para a Ação, Castillo (2002) conclama gatekeepers, editores e avaliadores de periódicos para disseminar ideias e discutir conhecimento tácito como fenômeno ou metáfora. De acordo com Polanyi e Prosch (1975), as metáforas, ao contrário de outros significados, fundem elementos incompatíveis em novas coerências.

Assim, a bricolagem seria a denominação opcional para a revisão de literatura no contexto acadêmico-científico e uma forma de coletar conhecimento pela visão de diversos autores, reunindoos com reflexão e gerando algo que, pela reunião de ideias, faça sentido para os autores que a propõe. Ela seria entendida como a gênese para criação de nova produção, cobrindo inicialmente a defasagem de conhecimento dos seus autores e, com base em tais defasagens, incitando-os à busca pela ampliação e preenchimento do gap de conhecimento. 


\subsection{Sense-making}

Polanyi (2009), ao discutir o paradoxo de Menon, argumenta que temos conhecimento, mas isso não dispensa a necessidade de ampliá-lo porque sabemos também o que nos falta, conduzindo-nos a identificar o gap à expectativa de encontrá-lo.

Tal modelo é constituído por categorias para descrever a maneira como as pessoas veem seu caminho bloqueado por algo à sua frente. Essas categorias foram nomeadas de situation-stop, a primeira parada é a decisão entre dois ou mais caminhos à frente; a barreira, quando a pessoa vê um caminho à frente, mas algo ou alguém está bloqueando-o; spin-out, quando não consegue enxergar um caminho; wash-out, quando o caminho desaparece repentinamente; e a problemática, quando a pessoa se vê no caminho que não escolheu. Para capturar as formas como as pessoas respondem a essas paradas, foram desenvolvidas categorias de ajuda: criação de ideias, localização de endereços ou maneiras de se mover, aquisição de competências, obtenção de apoio ou de confirmação, motivação para ficar conectado a outros, calma e relaxamento, sensação de prazer ou felicidade e alcance dos objetivos (DERVIN, 1992).

A abordagem de criação de significado oferece uma metáfora cognitiva para o uso da informação com estratégias para transpor o vazio e para ajudar a transpô-lo. Em síntese, Dervin (1992) enfatiza a importância da interação entre indivíduos para o questionamento sobre qual necessidade, em que termos a expressamos, qual informação pode suprir referida lacuna, onde encontrá-la ou onde obter ajuda em como encontrá-la.

Um exemplo da natureza do conhecimento nas organizações faz parte do estudo de Tsoukas (1996) em que ele explana que as práticas sociais das firmas de conhecimento consistem em três dimensões: expectativas relacionadas ao papel normativo, alienações formadas pelas socializações passadas e situações interativas (envolvendo o conhecimento local de circunstâncias particulares, de tempo e de espaço).

A visão do sense-making nas organizações focaliza como as pessoas constroem sentido dos seus mundos, como elas usam, buscam e criam conhecimento nesse processo, significando que, em qualquer das técnicas, há outros elementos envolvidos, como, por exemplo, contexto, circunstâncias pessoais ou sociais, espaço e tempo (CECEZ-KECMANOVIC, 2004).

\section{CONSIDERAÇÕES FINAIS}

Ao analisar as nuanças, é possível concluir que o conhecimento é algo intangível que existe na mente dos seres humanos, transmitido via contato pessoal. Também é um termo ambíguo que requer adjetivação para esclarecer seu sentido e ser utilizado, razão porque este artigo refere-se à variedade de termos para descrever o conhecimento.

O artigo expõe que qualquer das técnicas ou estratégias utilizadas para criação de conhecimento necessita de outras que a complementem. Uma CoP necessita de ambientes favoráveis, contexto adequado, no mínimo; ou, como exemplificado pela perspectiva de visão na organização, em que os companheiros estão estimulados por algo que pretendem construir e compartilhar e reunidos e mobilizados pelos ativistas do conhecimento, tendo como base as afinidades de itens de conhecimento. Por sua vez, as metáforas e a bricolagem dependem de autores que construíram, criaram e dispuseram conhecimento para compartilhar e do entendimento e compreensão dos autores que as utilizam. Em outras palavras, são dependentes dos sentidos que dão ao conhecimento que reconhecem como fazendo falta para completá-lo. Mas isso já é outra metáfora, pois o conhecimento é sempre incompleto e a busca, constante e permanente para que se possa ampliálo, criá-lo e recriá-lo.

As técnicas que se utilizam para facilitar os contatos e suas explicitações conduzem invariavelmente à criação e/ou ampliação do conhecimento. Na verdade, é disso que as organizações necessitam para inovar e se manter no mercado, sendo, portanto, esses os instrumentos de que dispõem e nos quais investem, especialmente em seus recursos humanos, para alcance do objetivo a que se propõem. Da mesma forma que há metodologias que estimulam a geração e a criação de conhecimento ou explicitação de conhecimento, e isso é o que pode ser gerido.

Repetindo o que foi dito, o conhecimento pode ser estimulado para ser criado, mas nunca gerenciado. As metodologias utilizadas referem-se à geração/criação de conhecimento, e ainda assim dependem de sentidos, contexto e ambiente favorável, para que produzam significado, possam ser aprendidos e apreendidos, e utilizados na geração de novos conhecimentos. E ainda assim sofrem 
influências psicológicas, sociais, técnicas e tecnológicas.

No afã a que nos dedicamos, buscamos, por meio das ideias de uma variedade de autores, entender o pensamento de Polanyi sobre conhecimento tácito e seus desdobramentos e as inerentes dificuldades teóricas e práticas que envolvem a aceitação do termo "gestão de conhecimento" como apropriado para o que, na verdade, são processos e métodos para promover a criação e socialização do conhecimento. Finalmente, apresentamos técnicas e estratégicas usadas na socialização, criação e ampliação de conhecimento utilizadas nas organizações e algumas expectativas para que o conhecimento individual também se promova e contribua socialmente, ou seja, do local para o global ou vice-versa.

Polanyi (1967) distingue três aspectos do conhecimento que o diferenciam. Em primeiro lugar, a verdadeira descoberta não pode ser explicada por um conjunto de regras ou algoritmos articulados; em segundo lugar, o conhecimento é público, mas é também, em grande medida, pessoal (ou seja, ele é socialmente construído); em terceiro lugar, o conhecimento que fundamenta o conhecimento explícito é mais fundamental. $\mathrm{O}$ autor finaliza ressaltando que todo conhecimento é tácito ou enraizado em conhecimento tácito.

\title{
NUANCES AND STRATEGIES SURROUNDING THE TACIT KNOWLEDGE
}

\begin{abstract}
This paper reflects upon knowledge management terminology controversies spread in several areas by Michael Polanyi's philosophical view about tacit knowledge and based on his insight "we know more than we can tell". For this author, tacit knowledge concerns the knowledge an individual acquired through his/her life experience; thus, it is subjective and consists of his/her personal skills that being the reason why it is hard to formalize. This is the main argument discussed in this study. From Polanyi's ideas, this study asks: Is it possible to manage knowledge? The literature review intentionally selected from business administration and information science presents divergent views on either management or creation of knowledge, and strategies employed by organizations to extend knowledge. The conclusion reached from the comparison between Polanyi's ideas and other authors is that those strategies - at least in the selected literature - focus on methodologies that lead to knowledge creation instead of knowledge management, as it is often so-called.
\end{abstract}

Keywords: Tacit knowledge. Michael Polanyi's Epistemology. Knowledge Creation. Knowledge Management.

\section{REFERÊNCIAS}

AN ILLUSTRATED guide of knowledge management. [2003]. Disponível em: <http://www.wmforum.org >. Acesso em: 10 jan. 2015.

ARROW, K. Economic welfare and the allocation of resources for innovation. In: LAMBERTON, D. (Ed.) Economics of information and knowledge. Harmondsworth: Penguin Books, 1971. p. 609-626.

BARRADAS, J. S.; CAMPOS FILHO, L. A. N. Levantamento de tendências em gestão do conhecimento no Brasil: análise de conteúdo da opinião de especialistas brasileiros. Persp. em Cl, Belo Horizonte, v. 15, n. 3, p. 131-154, set./dez. 2010.

BARRETO, A. A. Políticas de monitoramento da informação por compressão semântica dos seus estoques. DataGramaZero: Revista de Ciência da Informação, Rio de Janeiro, v. 4, n. 2, abr. 2003. Disponível em: <http://www.dgz.org.br>. Acesso em: 4 jun. 2015.

BIRKINSHAW, J. Why is knowledge management so difficult? Business Strategy Review, West Sussex, v. 12, n. 1, p. 11-18, 2001.

BROOKES, B. The foundations of information science. Part I: philosophical aspects. Journal of Information Science, London, v. 2, p. 112-133, 1980.

CASTILLO, J. A note on the concept of tacit knowledge. Journal of Management Inquiry, 
Thousand and Oaks, v. 11, n. 1, p. 46-57, Mar. 2002.

CECEZ-KECMANOVIC, D. A Sensemaking model of knowledge in organizations: a way of understanding knowledge management and the role of information technologies. Knowledge Management Research \& Practice, Ontario, n. 2, p. 155-168, 2004.

CERTEAU, M. de. A invenção do cotidiano: artes do fazer. Petrópolis: Vozes, 1994.

DERVIN, B. From the mind's eye of the user: the sense-making qualitative-quantitative methodology. In: GLAZIER, J. D.; POWELL, R. R. (Org.). Qualitative research in information management. Englewood: Libraries Unlimited, 1992. p. 61-842.

FORAY, Dominique; LUNDWALL, Bengt-Ake. The knowledge-based economy: from the economics of knowledge to the learning economy. Paris: OECD, 1996.

GOODMAN, C. P. The tacit dimension. Polanyiana, Yale, n. 1-2, p. 133-157, 2003.

GRANOVETTER, M. The Strength of Weak Ties. The American Journal of Sociology, Chicago, v. 78, n. 6, p. 1360-1380, May 1973.

HESSEN, J. Teoria do conhecimento. São Paulo: Martins Fontes, 2000.

JHA, S.R. Michael Polanyi's integrative philosophy. 1995. Tese (Doutorado em Educação) Harvard University, Boston, Thesis J47, 1995.

KLINT, P.; VERHOEF, C. Enabling the creation of knowledge about software assets. Data \& Knowledge Engineering, Amsterdam, v. 41, n. 2-3, p. 141-158, June 2002.

KROGH, G.; ICHIJO, K.; NONAKA, I. Enabling knowledge creation: how to unlock the mystery of tacit knowledge and release the power of innovation. Oxford: University Press, 2000.

LASTRES, H. M. M.; FERRAZ, J. C. Economia da informação, do conhecimento e do aprendizado. In: LASTRES, H. M. M.; ALBAGLI, S. (Org.) Informação e globalização na era do conhecimento. Rio de Janeiro: Campus, 1999. p. 27-57.

LEONARD, D.; SENSIPER, S. The role of tacit knowledge in group innovation. California Management Review, Berkeley, v. 40, n. 3, p. 112-132, 1998.

MINTZBERG, H.; AHLSTRAND, B.; LAMPEL, J. A escola cognitiva: a formação de estratégia como um processo mental. In: estratégico. Porto Alegre: Bookman, 2006.

NAVEGA, S. Por que gerenciar conhecimento é tão difícil? [2003]. Disponível em: <http://www. intelliwise.com/reports/info2003.pdf>. Acesso em: 4 jun. 2015.

NASCIMENTO, João, B. Estratégias de criação de conhecimento tecnológico em Icds na Sharp japonesa. In: SEMINÁRIOS EM ADMINISTRAÇÃO, 7., 2004, São Paulo. Anais... São Paulo: Faculdade de Economia e Administração da Universidade de São Paulo, 2004.

NONAKA, I.; TAKEUCHI, H. The knowledge-creating company: how Japanese companies create the dynamics of innovation. New York: Wiley, 1997.

NONAKA, I.; KONNO, N. The Concept of "Ba": building a foundation for knowledge creation, California Management Review, Berkeley, v. 40, n. 3, Spring 1998.

POLANYI, M. Personal knowledge: towards a post-critical philosophy. Chicago: The University of Chicago Press, 1962.

The logic of tacit inference. The Journal of The Royal Institute of Philosophy, Cambridge, v. 41, n. 155, p. 1-18, Jan. 1966.

Knowing and being: essays by Michael Polanyi. Chicago: The University of Chicago Press, 
The tacit dimension. London: The University of Chicago Press, 2009.

POLANYI, M.; PROSCH, H. Meaning. Chicago: The University of Chicago Press, 1975.

ROJAS, M. A. R. Relación entre lós conceptos: informatión, conocimiento y valor. Semejanzas y diferencias. Ciência da Informação, Brasília, v. 34 , n. 2, p. 52-61, maio/ago. 2005.

SAIANI, C. O valor do conhecimento tácito: a epistemologia de Michael Polanyi na escola. São Paulo: Escrituras, 2004.

SCHARTINGER, D. et al. Knowledge interactions between universities and industry in Austria: sectoral patterns and determinants. Research Policy, Amsterdam, v. 31, n. 3, p. 303-328, 2002.

SILVA, E. M. Gestão da informação para monitoramento de resultados no novo modelo gerencial do estado. In: DUARTE, E. N.; PAIVA, S. B.; SILVA, A. K. A. (Org.). Múltiplas abordagens de gestão da informação e do conhecimento no contexto acadêmico da Ciência da Informação. João Pessoa: Ed. UFPB, 2014. v. 1. p. 1-15.

SILVA, A. M. A informação: da compreensão do fenômeno e construção do objecto científico. Porto: Afrontamento, 2006.

SIMON, H. A. Administrative behavior. New York: Macmillan, 1957.

TORRES, C. R. Conocimiento explícito e implícito: dos formas distintas de pensamiento? [1998]. Disponível em: <http://www.efdeportes.com/efd10/torres10.htm>. Acesso em: 18 out. 2014.

TSOUKAS, $\mathrm{H}$. The firm as a distributed knowledge system. Strategic Management Journal, West Sussex, n. 17, p. 11-25, Winter Special Issue, 1996.

WENGER, E. Communities of practice. Learning, meaning and identity. Cambridge: Cambridge University Press, 1998. 